\title{
Transbuccal delivery of betahistine dihydrochloride from mucoadhesive tablets with a unidirectional drug flow: in vitro, ex vivo and in vivo evaluation
}

This article was published in the following Dove Press journal:

Drug Design, Development and Therapy

I4 December 2016

Number of times this article has been viewed

\author{
Mohamed A El-Nabarawi ${ }^{1}$ \\ Adel A Ali ${ }^{2}$ \\ Heba M Aboud ${ }^{2}$ \\ Amira $\mathrm{H}$ Hassan ${ }^{2}$ \\ Amany $\mathrm{H} \mathrm{Godah}^{2}$ \\ 'Department of Pharmaceutics, \\ Faculty of Pharmacy, Cairo University, \\ Cairo, ${ }^{2}$ Department of Pharmaceutics, \\ Faculty of Pharmacy, Beni-Suef \\ University, Beni-Suef, Egypt
}

Objective: Betahistine dihydrochloride ( $\mathrm{BH} .2 \mathrm{HCl})$, an anti-vertigo histamine analog used in the treatment of Ménière's disease, undergoes extensive first-pass metabolism and suffers from short biological half-life. The aim of the present work was to develop and estimate controlled release mucoadhesive buccal tablets of $\mathrm{BH} .2 \mathrm{HCl}$ with a unidirectional drug flow to overcome this encumbrance.

Methods: A direct compression method was adopted for preparation of the tablets using mucoadhesive polymers like guar gum, hydroxypropyl methyl cellulose K4M, sodium carboxymethyl cellulose and their combinations. The tablets were coated from all surfaces except one surface with a solution of $5 \%(\mathrm{w} / \mathrm{v})$ cellulose acetate and $1 \%(\mathrm{w} / \mathrm{v})$ dibutyl phthalate. Different permeation enhancers like $2 \%$ sodium deoxycholate, $2 \%$ sodium cholate hydrate $(\mathrm{SCH})$ and $5 \%$ menthol were tested. Swelling index, ex vivo residence time, mucoadhesion strength, in vivo testing of mucoadhesion time, in vitro dissolution and ex vivo permeation were carried out. Furthermore, compatibility and accelerated stability studies were performed for the drug excipients. Finally, drug bioavailability of the BH.2HCl-optimized buccal mucoadhesive formulation was compared with that of the orally administered Betaserc ${ }^{\circledR} 24 \mathrm{mg}$ tablet in six healthy male volunteers.

Results: Formulation F10, which contained a combination of 35\% guar gum and 5\% sodium carboxymethyl cellulose, exhibited long adhesion time, high adhesion strength and diminished irritation to volunteers and showed zero-order release kinetics. SCH produced a significant enhancement in permeation of $\mathrm{BH} .2 \mathrm{HCl}$ across buccal mucosa. $\mathrm{BH} .2 \mathrm{HCl}$-optimized buccal mucoadhesive formulation showed percentage relative bioavailability of $177 \%$.

Conclusion: The developed mucoadhesive tablets represent a promising alternative for the buccal delivery of $\mathrm{BH} .2 \mathrm{HCl}$.

Keywords: betahistine dihydrochloride, transbuccal delivery, unidirectional drug flow, permeation enhancer, relative bioavailability

\section{Introduction}

Mucoadhesive buccal delivery of drugs is considered as an alternative to oral administration, especially for drugs which suffer from first-pass metabolism. ${ }^{1}$ The buccal route can solve troubles encountered with oral administration of drugs such as considerable hepatic metabolism, drug decomposition in the gastrointestinal tract and avoidance of invasiveness of parenteral route. ${ }^{2}$ Several advantages of the buccal route have been reported, including: 1) robustness of the epithelium; 2) better accessibility; 3 ) easy removal of dosage form as needed and 4) relatively low susceptibility to enzymatic activity. ${ }^{3}$
Correspondence: Adel A Ali

Department of Pharmaceutics, Faculty of Pharmacy, Beni-Suef University, El Shahed Shehata Ahmed Hegazy St., Beni-Suef, Egypt

Tel +20822 317958

Email adel.ali@pharm.bsu.edu.eg 
On the other hand, there are some restrictions accompanied with the buccal administration, such as decreased retention time at the absorption site and the minimal flux, which leads to decreased drug bioavailability. Hence, incorporation of mucoadhesive polymers into buccal drug delivery systems is recently reported in different forms like adhesive tablets, ${ }^{4}$ adhesive films, ${ }^{5}$ adhesive patches ${ }^{6}$ and buccal gels. ${ }^{7}$ Additionally, coadministration with a penetration enhancer has been suggested for drugs that slowly or incompletely penetrate the oral mucosal membranes in order to reduce barrier properties of the buccal epithelium. Various kinds of prospective permeation enhancers are employed in buccal administration to enhance drug penetration. ${ }^{8}$ Buccoadhesives are widely utilized to ameliorate the bioavailability of drugs suffering extensive first-pass effect. ${ }^{9-11}$

Betahistine dihydrochloride (BH.2 $\mathrm{HCl})$ is an orally active histamine analog which has been used to control vertigo, lack of hearing and tinnitus related to Ménière's disease. The mechanism of $\mathrm{BH} .2 \mathrm{HCl}$ is to reduce the pressure of the membranous labyrinth that results in enhancement of the microvasculature circulation and improves the signs of Ménière's disease. Peroral administration undergoes extensive first-pass metabolism and gastric irritation in patients with peptic ulcer. In treatment of vertigo, a uniform and constant supply of drug is required in order to maintain steady-state concentration of the drug in the body. Unfortunately, $\mathrm{BH} .2 \mathrm{HCl}$ possesses a short half-life of about 3-4 $\mathrm{h}$ and requires frequent administration of the drug, ${ }^{12-15}$ thereby making it an ideal candidate for controlled release preparations.

Incorporation of a drug into a matrix system is a suggested method for modulation of its release. Hydrophilic polymer matrix systems are characterized by their flexibility, so they are commonly incorporated into controlled drug delivery systems to provide an ideal release profile of a drug. ${ }^{16}$ However, for hydrophilic drugs, simple drug mixing with the polymers may not satisfy the requirements of controlled release; hence, the prepared tablets were coated with cellulose acetate from all sides except one side, so that a unidirectional controlled drug release could be achieved.

Several studies have been carried out to control BH.2HCl release as well as to explore a new route for its administration like the transdermal route. ${ }^{13,15}$ To the best of our knowledge, this is the first study to explore the buccal route for $\mathrm{BH} .2 \mathrm{HCl}$ release with in vivo testing in human volunteers.

The aim of the current investigation was to design controlled release mucoadhesive tablets for buccal delivery of $\mathrm{BH} .2 \mathrm{HCl}$ with a unidirectional drug flow, thus improving its therapeutic efficiency, tolerability and patient compliance.

\section{Materials and methods}

\section{Materials}

BH.2HCl was kindly supplied by EIPICO (Cairo, Egypt). Hydroxypropyl methyl cellulose (HPMC) grade K4M, guar gum, sodium carboxymethyl cellulose (Na CMC) and dibutyl phthalate were purchased from Fluka (Munich, Germany). Cellulose acetate (39.8 wt. \% acetyl content, average $\mathrm{MN} \sim 30,000$ ), sodium deoxycholate (SDC), sodium cholate hydrate $(\mathrm{SCH})$, acetonitrile, sodium acetate, methanol and formic acid (high-performance liquid chromatography [HPLC] grade) were purchased from Sigma-Aldrich Co. (St Louis, MO, USA). Dialysis bags with a molecular weight cutoff of 12,000 Da were purchased from SERVA Electrophoresis GmbH (Heidelberg, Germany). Mannitol, magnesium stearate, colloidal silicon dioxide (Aerosil 200), magnesium carbonate and menthol were purchased from ADWIC (Cairo, Egypt). The other used ingredients were of analytical grade.

\section{Methods}

\section{Formulation of mucoadhesive buccal tablets Fabrication of core tablets}

A direct compression technique was employed for preparation of $\mathrm{BH} .2 \mathrm{HCl}$ mucoadhesive buccal tablets. The tested mucoadhesive polymers were HPMC K4M, guar gum and $\mathrm{Na}$ CMC. The composition of the prepared formulations is shown in Table 1. All the powders were passed through a No 60 sieve. A calculated amount of drug, different polymer mixtures and diluents were blended using a mortar and pestle up to $15 \mathrm{~min}$, so that a uniform mixture could be obtained. Lubrication of the blend was done using magnesium stearate for 3-5 min. Direct compression of the mixed blend at $8 \mathrm{kN}$ compression force into $150 \mathrm{mg}$ tablets was carried out using single punch tablet press (Shanghai Tianhe, Shanghai, People's Republic of China) fitted with a $10 \mathrm{~mm}$ flat punch and die set. Each tablet contained $24 \mathrm{mg}$ of $\mathrm{BH} .2 \mathrm{HCl}$.

\section{Tablet coating}

A diagrammatic sketch of the mucoadhesive tablets with a unidirectional drug flow is shown in Figure 1. Coating of all tablet formulations was performed from all sides except one face (the mucoadhesive side) with a polymeric solution composed of $5 \%(\mathrm{w} / \mathrm{v})$ cellulose acetate and $1 \%(\mathrm{w} / \mathrm{v})$ dibutyl phthalate in acetone ${ }^{17}$ using dip-coating process. ${ }^{18}$ The tablets were attached on one face to polytetrafluoroethylene adhesive tape, dipped into the coating solution, and then air dried under ambient conditions, and the process was repeated till there was a $10 \%$ increase in weight. The prepared tablets were stored in airtight containers for further study. 
Table I Composition of $\mathrm{BH} .2 \mathrm{HCl}$ mucoadhesive buccal tablets

\begin{tabular}{|c|c|c|c|c|c|c|c|c|c|c|c|c|}
\hline \multirow[t]{2}{*}{ Ingredients (mg)* } & \multicolumn{12}{|c|}{ Formulations } \\
\hline & $\mathbf{F} \mathbf{I}$ & $\mathbf{F 2}$ & F3 & F4 & $\mathbf{F 5}$ & F6 & $\mathbf{F 7}$ & $\mathbf{F 8}$ & F9 & FIO & F I I & FI 2 \\
\hline $\mathrm{BH} .2 \mathrm{HCl}$ & 24 & 24 & 24 & 24 & 24 & 24 & 24 & 24 & 24 & 24 & 24 & 24 \\
\hline HPMC K4M & 37.5 & 45 & 52.5 & - & - & - & 22.5 & 30 & 37.5 & - & - & - \\
\hline Guar gum & - & - & - & 60 & 67.5 & 75 & 22.5 & 30 & 37.5 & 52.5 & 52.5 & 52.5 \\
\hline $\mathrm{Na} C M C$ & - & - & - & - & - & - & - & - & - & 7.5 & 15 & 22.5 \\
\hline Aerosil 200 & 15 & 15 & 15 & 15 & 15 & 15 & 15 & 15 & 15 & 15 & 15 & 15 \\
\hline Mg carbonate & 7.5 & 7.5 & 7.5 & 7.5 & 7.5 & 7.5 & 7.5 & 7.5 & 7.5 & 7.5 & 7.5 & 7.5 \\
\hline Mg stearate & 1.5 & 1.5 & 1.5 & 1.5 & $\mathrm{I} .5$ & $\mathrm{I} .5$ & 1.5 & 1.5 & 1.5 & 1.5 & 1.5 & 1.5 \\
\hline Mannitol up to & 150 & 150 & 150 & 150 & 150 & 150 & 150 & 150 & 150 & 150 & 150 & 150 \\
\hline
\end{tabular}

Note: *All tablets are coated from all sides with a solution of $5 \%(\mathrm{w} / \mathrm{v})$ cellulose acetate and I\% (w/v) dibutyl phthalate except for one face.

Abbreviations: $\mathrm{BH} .2 \mathrm{HCl}$, betahistine dihydrochloride; HPMC K4M, hydroxypropyl methyl cellulose grade K4M; Na CMC, sodium carboxymethyl cellulose.

\section{Characterization of mucoadhesive $\mathrm{BH} .2 \mathrm{HCl}$ tablets \\ Uniformity of tablet weight}

The mean weight of 10 individually preweighed tablets from each formulation batch was calculated.

\section{Uniformity of tablet thickness and diameter}

A digital Vernier caliper (Shanghai, People's Republic of China) was used for measurement of the thickness and diameter of 10 tablets from each batch, and the results were presented as the mean ( \pm standard deviation $[\mathrm{SD}]$ ) of 10 measurements.

\section{Content uniformity}

In this test, 10 tablets were used where each tablet was mashed and transferred into $100 \mathrm{~mL}$ volumetric flask. The flasks were brought to volume by phosphate buffer $\mathrm{pH}$ 6.8. Each flask was sonicated using Sonix IV SS-Series (Sonix IV Ultrasonic Cleaning Systems, North Charleston, SC, USA) till dissolution occurred. Then $1 \mathrm{~mL}$ of the solution was filtered, suitably diluted, and final absorbance of the solution was measured at $260 \mathrm{~nm}$ using a UV spectrophotometer (V-530; Jasco, Tokyo, Japan) against phosphate buffer (pH 6.8) as a blank.

\section{Friability test}

Ten tablets were previously weighed, transferred to the drum of the friabilator (Pharma Test, Hainburg, Germany), rotated at $25 \mathrm{rpm}$ for $4 \mathrm{~min}$ and finally reweighed. The percentage loss in weights was calculated and taken as a measure of friability. ${ }^{19}$

\section{Hardness}

From each formulation, 10 tablets were tested for their hardness using a hardness tester (Dr Schleuniger Pharmatron, Manchester, NH, USA). The mean hardness ( \pm SD) of each formulation was determined in $\mathrm{kg} / \mathrm{cm}^{2} .{ }^{19}$

\section{Surface $\mathrm{pH}$}

The tablets were kept in distilled water to allow swelling for a period of $2 \mathrm{~h}$ at room temperature. The $\mathrm{pH}$ was measured by bringing the $\mathrm{pH}$ meter electrode (Jenway, Staffordshire, UK) in contact with the tablet surface after being equilibrated for $1 \min ^{20}$

\section{Swelling study}

The tablets were weighed and transferred individually into Petri dishes filled with $20 \mathrm{~mL}$ of phosphate buffer (pH 6.8), and the study was conducted for $10 \mathrm{~h}$. Then the tablets were removed from the Petri dishes and excess water was wiped off by a filter paper. The test was done in triplicate. The swelling index was calculated by applying the following equation:

$$
\text { Swelling index }=\frac{W_{2}-W_{1}}{W_{1}} \times 100,
$$

where $W_{1}$ is the buccal tablet weight before being dipped into the Petri dish and $W_{2}$ is the buccal tablet weight after being dipped and wiped. ${ }^{21}$

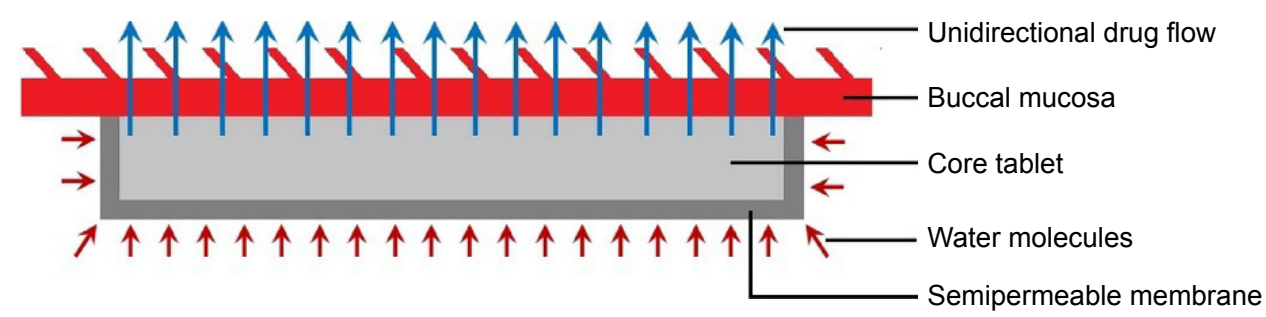

Figure I Diagrammatic sketch of mucoadhesive buccal tablet with a unidirectional drug flow. 


\section{Mucoadhesive strength}

The modified physical balance method was adopted for determination of the mucoadhesive strength of the tablets. The camel buccal mucosa was sectioned and cleaned with ringer solution. A section of camel buccal mucosa was fixed on an adjustable pan with cyanoacrylate glue keeping the mucosal side out on the upper adjustable pan and the adjustable pan with the camel buccal mucosa was kept at $37^{\circ} \mathrm{C}$ for $10 \mathrm{~min}$. The buccal tablets $(n=3)$ were glued to the lower fixed pan keeping the adhesive side of tablet facing upward. The height of the upper pan was adjusted so that the camel buccal mucosa can adhere to the tablet on the lower fixed pan. A constant force was applied on the upper pan for $2 \mathrm{~min}$, and was then detached and weighed. The weight on the right side pan was slowly increased, till the tablet detached from the mucosa. The mucoadhesive force $\left(\mathrm{dyne} / \mathrm{cm}^{2}\right)$ was determined using the minimal weight that caused detachment of the mucosal tissue from the tablet surface.

$$
\text { Mucoadhesive force }\left(\text { dyne } / \mathrm{cm}^{2}\right)=\frac{m g}{A}
$$

where $m=$ weight in grams required for detachment, $g=$ acceleration due to gravity $\left(980 \mathrm{~cm} / \mathrm{s}^{2}\right)$ and $A=$ area of mucosal surface exposed that equals the tablet area. ${ }^{22}$

\section{Ex vivo residence time}

Disintegration apparatus (Hanson Research, Chatsworth, CA, USA) was used for determination of ex vivo residence time of the prepared tablets. Phosphate buffer ( $\mathrm{pH}$ 6.8, 800 $\mathrm{mL}$ ) was used as disintegration medium and was maintained at $37^{\circ} \mathrm{C} \pm 0.5^{\circ} \mathrm{C}$. Camel buccal mucosa segment was glued to a glass slab surface and then brought in a vertical attachment to the apparatus. Hydration of three mucoadhesive tablets of each formulation was carried out using phosphate buffer (pH 6.8) on one surface, the mucosal membrane was kept in contact with the hydrated surface, and the apparatus was allowed to move up and down. The required time for detaching the tablet from the surface was recorded. ${ }^{23}$

\section{In vivo mucoadhesive performance of buccal tablets}

This study was conducted after obtaining permission from the Ethical Committee of Beni-Suef University and then written informed consent was obtained from all the volunteers before conducting the study. The in vivo mucoadhesive performance test was carried out in three healthy volunteers aged $20-35$ years. The buccal tablets $(n=3)$ were adhered, just above the canine tooth, to the gingival mucosa by pressing for $30 \mathrm{~s}$ onto mucosa and kept for a period of $16 \mathrm{~h} .{ }^{24}$ The volunteers were claimed to note:

1) The adhesion time: time required for the tablet to detach from the buccal mucosal surface

2) The adhesion strength (unadhesive, slightly adhesive, adhesive or very adhesive)

3) Any irritation signs (non-irritant, slight, moderate or severe)

4) Bitter taste as a result of $\mathrm{BH} .2 \mathrm{HCl}$ swallowing (non, slight, moderate or very)

5) The mucoadhesive tablet disintegration in the buccal cavity (non, slight, moderate or high)

\section{In vitro release study}

Vertical diffusion Franz cells, with a diffusion area of $5 \mathrm{~cm}^{2}$, were used for in vitro release studies. The receptor compartment which contained $50 \mathrm{~mL}$ of phosphate buffer (pH 6.8) was maintained at $37^{\circ} \mathrm{C} \pm 0.5^{\circ} \mathrm{C}$ and stirred at $100 \mathrm{rpm}$ by a magnetic bar. The mucoadhesive tablets containing $24 \mathrm{mg}$ drug were introduced in the donor compartment. Cellulose dialyzing membrane having a molecular weight cutoff of $12,000 \mathrm{Da}$ was soaked in phosphate buffer ( $\mathrm{pH}$ 6.8) overnight and used for the separation of the donor compartment from the receptor one. ${ }^{25}$ One milliliter aliquots were taken at predetermined time intervals $(1,2,3,4,5,6$ and $8 \mathrm{~h})$, and a constant volume was maintained by replacing with fresh medium of equal volume. The samples were filtered through a $0.45 \mu \mathrm{m}$ millipore filter and analyzed spectrophotometrically at $260 \mathrm{~nm}$ after being appropriately diluted. The cumulative amount of released drug in the preparations was calculated using the calibration equation. The experiments were repeated in triplicate $(n=3)$ in a similar manner.

The order of drug release was determined by performing kinetic analysis of the release data. Higuchi diffusion, Korsmeyer-Peppas models as well as zero- and first-order kinetics were employed, and the values of correlation coefficient $\left(R^{2}\right)$ were computed.

\section{Ex vivo permeation study}

This study was approved by the local Animal Ethics Committee of Beni-Suef University. Camel buccal mucosa was procured from a local slaughter house and used within $1 \mathrm{~h}$ of slaughter. The tissue was stored in phosphate buffer saline, $\mathrm{pH} 6.8$, at $4^{\circ} \mathrm{C}$ after collection. The epithelium was separated from underlying connective tissues with surgical scissors, and the mucosa thickness was found to be $0.2 \pm 0.1 \mathrm{~mm}$. The tablets were evaluated for drug permeation using vertical diffusion Franz cells. ${ }^{26}$ Camel buccal membrane was mounted 
between the donor and receptor compartments. The diffusion cell was placed in a water bath maintained at $37^{\circ} \mathrm{C} \pm 0.5^{\circ} \mathrm{C}$. The buccal tablet placed into the donor compartment was wetted with $1 \mathrm{~mL}$ of phosphate buffer ( $\mathrm{pH}$ 6.8). The receptor compartment containing $50 \mathrm{~mL}$ of phosphate buffer (pH 6.8) was stirred with a magnetic bead at $100 \mathrm{rpm} .^{27,28}$

The diffusion study was performed for $8 \mathrm{~h}$. The permeated amount of $\mathrm{BH} .2 \mathrm{HCl}$ via the membrane was determined by periodical removal of samples followed by replacement with fresh buffer of an equal volume. Filtration and suitable dilution of the withdrawn aliquots were performed followed by spectrophotometrical analysis at $260 \mathrm{~nm}$. A trial was made to show the degree of permeation of $\mathrm{BH} .2 \mathrm{HCl}$ from its buccal mucoadhesive tablet (formulation F10). Two percent $\mathrm{SCH}$, $2 \% \mathrm{SDC}$ and $5 \%$ menthol were incorporated as permeation enhancers and were used separately in the chosen formulation. The experiments were performed in triplicate $(n=3)$ and mean of triplicate was determined.

The permeation parameters were obtained by graphical plotting of the permeation data of $\mathrm{BH} .2 \mathrm{HCl}$ as the cumulative amount of drug permeated per unit area as a function of time. The cumulative drug in the receptor compartment after $8 \mathrm{~h}$ was defined as $Q_{\text {cum }}\left(\mu \mathrm{g} / \mathrm{cm}^{2}\right)$. The permeability coefficient $K_{\mathrm{p}}$ $(\mathrm{cm} / \mathrm{h})$ of $\mathrm{BH} .2 \mathrm{HCl}$ from each formulation can be calculated by dividing the slope of the straight line portion of the curve by the originally added drug concentration. The lag time could be obtained from the X-intercept of the linear part of the graph. ${ }^{29}$

The effectiveness of the various enhancers was obtained by comparison of certain permeation parameters of $\mathrm{BH} .2 \mathrm{HCl}$ in the absence or presence of enhancer. This ratio was known as the enhancement factor (EF) and was determined from the following equation: ${ }^{30}$

$$
\mathrm{EF}=\frac{K_{\mathrm{p}}(\text { enhanced })}{K_{\mathrm{p}}(\text { control })}
$$

where $K_{\mathrm{p}}$ (enhanced) is the permeability coefficient for tablets in the presence of enhancer and $K_{\mathrm{p}}$ (control) is the permeability coefficient for tablets without enhancer.

\section{Compatibility studies \\ Differential scanning calorimetry (DSC)}

DSC analysis of the plain drug and the drug with additives (formulation $\mathrm{F} 10$ in addition to $\mathrm{SCH}$ ) were performed using DSC (TA-60WSI; Shimadzu, Tokyo, Japan). Samples of 5 mg were hermetically sealed in flat-bottom aluminum pans and heated in a nitrogen atmosphere for elimination of the pyrolytic and oxidative effects in the DSC instrument. A temperature range of $25^{\circ} \mathrm{C}-300^{\circ} \mathrm{C}$ and a heating rate of $5^{\circ} \mathrm{C} / \mathrm{min}$ were adopted. The DSC thermograms were recorded.

\section{Fourier-transform infra red spectroscopy}

The infrared (IR) spectra of the pure drug and the drug with additives (formulation $\mathrm{F} 10$ in addition to $\mathrm{SCH}$ ) were recorded on an FTIR spectrophotometer (Shimadzu IR-345). Samples of 2-3 mg were mixed with about $400 \mathrm{mg}$ of dry potassium bromide and then compressed into transparent discs under pressure of 10,000-15,000 psi. The IR spectra were recorded at a scanning range of $400-4,000 \mathrm{~cm}^{-1}$ and resolution of $4 \mathrm{~cm}^{-1}$.

\section{Stability testing \\ Accelerated stability testing}

Accelerated stability studies on BH.2HCl-optimized buccal mucoadhesive formulation (formulation F10 in addition to $\mathrm{SCH})$ were performed by keeping the tablets in PVC blisters wrapped with aluminum foil and storing at $40^{\circ} \mathrm{C}$ and $60^{\circ} \mathrm{C}$ with $75 \%$ relative humidity in oven for 12 weeks. Periodical examination of the samples at 1, 2, 4, 6, 8 and 12 weeks was carried out for any physical changes as well as for their drug content using HPLC stability indicating method. ${ }^{31}$

Kinetic analysis of the stability data was carried out for the determination of drug degradation order according to zero- and first-order kinetics. At each of the two temperatures, the reaction rate constant $(K)$ was calculated according to a determined order. Plotting of the logarithmic $K$ values at various temperatures against the reciprocal of the corresponding temperature according to Arrhenius plot was performed for the expiration date determination..$^{32-34}$

The analyses were carried out using the technique of liquid chromatography (Agilent 1260 Infinity; Agilent, Waldbronn, Germany), equipped with Agilent 1260 Infinity Diode Array Detector VL (G 1315D), Agilent 1260 Infinity Preparative Pump (G 1361A), Agilent 1260 Infinity Thermostatted Column Compartment (G 1316A) and Agilent 1260 Infinity Preparative Autosampler (G 2260A). Separation and quantification were performed on $\mathrm{C} 18$ column (Zorbax Eclipse Plus; $25 \mathrm{~cm} \times 4.6 \mathrm{~mm}$ internal diameter [id], $5 \mu \mathrm{m}$ particle size). The mobile phase was a mixture of $30 \%$ acetonitrile and $70 \%$ sodium acetate $(0.02 \mathrm{~mol} / \mathrm{L}, \mathrm{pH} 4.5)$ for $1 \mathrm{~min}$ and linear gradient elution from 1 to $21 \mathrm{~min}$ to end with $70 \%$ acetonitrile and $30 \%$ sodium acetate solution. The mobile phase was filtered by passing through a $0.45 \mu \mathrm{m}$ membrane filter, degassed and delivered at a flow rate of $1 \mathrm{~mL} / \mathrm{min}$. Detection was carried out at a wavelength of $260 \mathrm{~nm}$ at ambient temperature. Calibration curve was constructed over a concentration range of $2-14 \mu \mathrm{g} / \mathrm{mL}$. 
Effect of humid storage on the release and mucoadhesive strength of $\mathrm{BH} .2 \mathrm{HCl}$ from stored tablet

In order to examine the influence of storage at high humidity and temperature on $\mathrm{BH} .2 \mathrm{HCl}$ release from the selected formulation, release study was performed on tablets obtained from the stored formulation at $40^{\circ} \mathrm{C}$ and $75 \%$ relative humidity after 4,8 , and 12 weeks as described earlier.

For studying the influence of storage at high humidity and temperature on the mucoadhesive strength of the BH.2 $\mathrm{HCl}$ selected formulation, mucoadhesive strength was determined using the modified physical balance method as described earlier.

\section{Bioavailability assessment of $\mathrm{BH} .2 \mathrm{HCl}$ from selected mucoadhesive tablet formulation \\ Study design}

The study was carried out to compare the pharmacokinetics of BH.2HCl from the optimized buccal tablet (F10 in addition to $\mathrm{SCH}$, treatment $\mathrm{A}$ ) to that of the commercially available oral Betaserc $^{\circledR}$ (Betahistine dihydrochloride) $24 \mathrm{mg}$ tablet (Solvay Pharmaceuticals, Brussels, Belgium; treatment B) following administration of a single dose $(24 \mathrm{mg})$ using randomized crossover design. Six healthy male volunteers $(60-70 \mathrm{~kg}$, age 20-30 years) were included in the study; they gave written informed consent and were arbitrarily divided into two groups of equal size. The chosen volunteers were non-alcoholics and non-smokers. The biochemical examination of the volunteers revealed normal liver and kidney functions. The nature and purpose of the study were fully explained to them. The study was approved by the Ethical Committee of Beni-Suef University. The selected buccal formulation of $\mathrm{BH} .2 \mathrm{HCl}$ was attached to the buccal mucosa of the healthy human volunteers for $8 \mathrm{~h}$, and Betahistine dihydrochloride $24 \mathrm{mg}$ tablet was administered perorally with $200 \mathrm{~mL}$ water. Buccal and oral drug administration was carried out after overnight fasting and a 1-week washout period. Venous blood samples $(5 \mathrm{~mL})$ were collected in heparinized tubes at the following time intervals: $0.5,2.5,5,8.5,14$ and $20 \mathrm{~h}$ after drug administration. Plasma was separated by centrifugation at $3,000 \mathrm{rpm}$ for $10 \mathrm{~min}$ and stored at $-20^{\circ} \mathrm{C}$ until further analysis.

\section{Chromatographic conditions}

Plasma samples were analyzed for $\mathrm{BH} .2 \mathrm{HCl}$ by adopting a modified ultra-performance liquid chromatography/ tandem mass spectrometry (UPLC/MS/MS) method. ${ }^{35}$ The mobile phase, a mixture of methanol and $0.1 \%$ formic acid $(90: 10 \mathrm{v} / \mathrm{v})$, was run at a flow rate of $0.25 \mathrm{~mL} / \mathrm{min}$.
The column effluent was monitored using MS/MS in a positive electrospray ionization mode, using $25 \mathrm{eV}$ cone voltage and $15 \mathrm{eV}$ colliding energy. Multiple reaction monitoring mode was employed for the quantification; $\mathrm{m} / \mathrm{z}$ $137.1 \rightarrow 94.08$ for BH.2HCl and $\mathrm{m} / \mathrm{z} 306.05 \rightarrow 261.19$ for the IS (dapoxetine) with a dwell time of $0.146 \mathrm{~s}$ per transition. The gas temperature was $400^{\circ} \mathrm{C}$, and the gas flow rate was $400 \mathrm{~L} / \mathrm{h}$. The full system consisted of an Acquity UPLC ${ }^{\text {TM }}$ system (Waters Corporation, Milford, MA, USA), a Quattro Premier XE Mass Spectrometer (Waters Corporation), Waters Mass Lynx ${ }^{\mathrm{TM}}$ Software Version 4.1 and an Acquity UPLC ${ }^{\mathrm{TM}}$ BEH Shield RP18 column, $130 \AA$, $1.7 \mu \mathrm{m}$, $2.1 \times 100 \mathrm{~mm}$ column (Waters Corporation).

\section{Sample preparation for analysis}

The frozen human samples were left to be thawed at room temperature. A solvent extraction procedure was used. Human plasma samples $(500 \mu \mathrm{L})$ were mixed with $50 \mu \mathrm{L}$ of $\mathrm{NaOH}(0.4 \mathrm{~N})$ and $50 \mu \mathrm{L}$ of stock solution of the internal standard and then vortexed for $30 \mathrm{~s}$. Five milliliters of methyl-ter-butyl ether was added, and samples were then vortexed for $1 \mathrm{~min}$. The tubes were centrifuged for $5 \mathrm{~min}$ at $4,000 \mathrm{rpm}$. The upper organic phases were then transferred to clean glass tubes and evaporated to dryness at $60^{\circ} \mathrm{C}$.

Dry residues were dissolved in $100 \mathrm{~mL}$ of methanol and vortexed for $1 \mathrm{~min}$ to reconstitute the residues, and $7.5 \mu \mathrm{L}$ was injected using the autosampler. The $\mathrm{BH} .2 \mathrm{HCl}$ recovery $(0.05-200 \mathrm{ng} / \mathrm{mL})$ varied between $94.45 \%$ and $100.53 \%$. The linearity was observed between 0.05 and $200 \mathrm{ng} / \mathrm{mL}$ $\left(R^{2}=0.9931 ; \mathrm{n}=8\right)$.

\section{Data analysis}

WinNonlin ${ }^{\circledR}$ Version 1.5 (Scientific Consulting, Inc., Gaithersburg, MD, USA) was used for estimation of pharmacokinetic parameters for each subject after administration of the tested treatments. Non-compartmental analysis was applied. $t_{\text {max }}(\mathrm{h})$ and $c_{\text {max }}(\mathrm{ng} / \mathrm{mL})$ were the time needed to reach the maximal concentration and the maximal drug concentration, respectively. Trapezoidal rule was used for calculation of the area under the curve (AUC) from zero time to the last time of the blood sample, $\mathrm{AUC}_{0-20}(\mathrm{ng} \cdot \mathrm{h} / \mathrm{mL})$.

$\mathrm{AUC}_{0-\infty}(\mathrm{ng} \cdot \mathrm{h} / \mathrm{mL})$, the $\mathrm{AUC}$ from zero to infinity, was calculated as $\mathrm{AUC}_{0-\infty}=\mathrm{AUC}_{0-20}+C_{\mathrm{t}} / k$, where $C_{\mathrm{t}}$ is the last concentration at time $\mathrm{t}$, and $k$ is the terminal elimination rate constant estimated by log-linear regression analysis on visually assessed data at terminal log-linear phase. Apparent terminal elimination half-life $\left(t_{1 / 2}\right)$ was calculated as $t_{1 / 2}=0.693 / k$. 


\section{Statistical studies}

The significance of the difference between the pharmacokinetic parameters of the different formulations was assessed using one-way analysis of variance. The significance level was set at 0.05 using Statistical Package for the Social Sciences (SPSS) Version 22 software computer program.

\section{Results and discussion Characterization of mucoadhesive $\mathrm{BH} .2 \mathrm{HCl}$ tablets}

Table 2 shows that all the formulated $\mathrm{BH} .2 \mathrm{HCl}$ mucoadhesive buccal tablets exhibited low weight variation that ranged from $149.6 \pm 0.98$ to $151.9 \pm 0.36 \mathrm{mg}$.

The developed tablets (F1-F12) had thickness in the range of $1.58 \pm 0.06$ to $1.69 \pm 0.11 \mathrm{~mm}$, while the tablets' diameter ranged from $10.03 \pm 0.052$ to $10.13 \pm 0.021 \mathrm{~mm}$. The drug content varied from $98.0 \% \pm 0.70 \%$ to $102.1 \% \pm 0.65 \%$, which was within the required limits. ${ }^{36}$

Friability of the prepared tablets varied from $0.15 \%$ to $0.77 \%$ loss and did not exceed the permissible limit of $1 \%{ }^{37}$ The hardness values ranged from 3 to $4.36 \mathrm{~kg} / \mathrm{cm}^{2}$ with $\mathrm{SD}<2 \%$ for all the prepared tablets.

All the formulations exhibited surface $\mathrm{pH}$ values ranging from 6.04 to 7.68. For investigation of possible in vivo irritation effects, the surface $\mathrm{pH}$ of buccal tablets was determined because alkaline or acidic $\mathrm{pH}$ might irritate the buccal mucosa. Surface $\mathrm{pH}$ of the prepared formulations was found to be close to neutral $\mathrm{pH}$. It was reported that neutral $\mathrm{pH}$ of the formulations does not give rise to any mucosal irritation effects. $^{20}$

\section{Swelling study}

The swelling extent of mucoadhesive polymers can be considered as an essential factor influencing adhesion. Adhesion starts to occur after a short time of tablet swelling; however, weak bonds are formed. ${ }^{38}$ Relaxation of the polymer chains which are present in stretched, twisted or entangled condition occurs as a result of water uptake, leading to exposure of the mucoadhesive sites of the polymer for bonding to occur. Rapid polymer swelling results in fast mucoadhesion as a result of rapid initiation of diffusion and formation of adhesive bonds ${ }^{39}$ Results showed that formulations containing HPMC (F1-F3) showed lower values than those containing guar gum (F4-F6) (Table 2). Also, the results revealed that formulations containing higher concentration of the polymers (F3 and F6) exhibited lower swelling index, which could be attributed to restriction of movement of the polymers as a result of their high concentration. ${ }^{40}$

Moreover, incorporation of $\mathrm{Na} \mathrm{CMC}$ increased the swelling index of the prepared formulations (F9-F12). Polyanionic polymers like $\mathrm{Na} \mathrm{CMC}$ have carboxylic groups that form hydrogen bonds with mucosal membrane. Fast hydration rate of $\mathrm{Na} \mathrm{CMC}$ resulted in higher extent of swelling in short time, which enhanced entanglement of chains of the polymer with mucus as reported by Lehr et al. ${ }^{41}$ The highest swelling index was obtained in formulation F12 which contained a mixture of $35 \%$ guar gum and $15 \% \mathrm{Na}$ CMC. Our results are in accordance with Shanker et $\mathrm{a}^{42}$ who reported higher swelling of buccal tablets of tizanidine hydrochloride with increasing $\mathrm{Na} \mathrm{CMC}$ content and also lower swelling with higher HPMC $\mathrm{K} 4 \mathrm{M}$ content. The comparison of percentage swelling of the prepared formulations is shown in Figure 2A and B.

\section{Mucoadhesion strength and ex vivo residence time}

The mucoadhesive force of the prepared formulations was measured using the modified balance method. A contact time of 15 min was adopted during the measurement of

Table 2 Physicochemical parameters of the developed $\mathrm{BH} .2 \mathrm{HCl}$ mucoadhesive buccal tablets

\begin{tabular}{|c|c|c|c|c|c|c|c|c|}
\hline Formulations & $\begin{array}{l}\text { Mean weight } \\
(\mathrm{mg}) \pm \mathrm{SD}\end{array}$ & $\begin{array}{l}\text { Mean diameter } \\
(\mathbf{m m}) \pm \mathbf{S D}\end{array}$ & $\begin{array}{l}\text { Mean thickness } \\
(\mathbf{m m}) \pm \text { SD }\end{array}$ & $\begin{array}{l}\% \text { drug } \\
\text { content } \pm \text { SD }\end{array}$ & $\%$ friability & $\begin{array}{l}\text { Hardness } \\
\left(\mathbf{k g} / \mathrm{cm}^{2}\right) \pm \mathrm{SD}\end{array}$ & Surface pH & \% swelling \\
\hline $\mathrm{FI}$ & $150.40 \pm 0.54$ & $10.03 \pm 0.05$ & $1.62 \pm 0.19$ & $100.29 \pm 1.36$ & 0.77 & $3.00 \pm 0.24$ & $7.49 \pm 0.09$ & $\mid 35.57 \pm 1.50$ \\
\hline $\mathrm{F} 2$ & $149.62 \pm 0.98$ & $10.04 \pm 0.04$ & $1.69 \pm 0.11$ & $101.32 \pm 0.63$ & 0.75 & $3.22 \pm 0.27$ & $7.50 \pm 0.26$ & $132.20 \pm 0.98$ \\
\hline F3 & $150.22 \pm 0.63$ & $10.07 \pm 0.03$ & $1.69 \pm 0.07$ & $100.10 \pm 0.58$ & 0.69 & $3.39 \pm 0.14$ & $7.68 \pm 0.43$ & $129.46 \pm 1.10$ \\
\hline $\mathrm{F} 4$ & $|5| .|4 \pm 0.5|$ & $10.08 \pm 0.04$ & $1.63 \pm 0.09$ & $101.49 \pm 0.84$ & 0.29 & $4.29 \pm 0.13$ & $7.0 \mathrm{I} \pm 0.20$ & $|47.40 \pm| .04$ \\
\hline F5 & $150.29 \pm 0.98$ & $10.08 \pm 0.03$ & $1.63 \pm 0.05$ & $101.00 \pm 1.50$ & 0.21 & $4.35 \pm 0.11$ & $6.66 \pm 0.26$ & $145.25 \pm 1.77$ \\
\hline F6 & $149.78 \pm 1.49$ & $10.13 \pm 0.02$ & $1.69 \pm 0.07$ & $98.03 \pm 0.70$ & 0.15 & $4.36 \pm 0.12$ & $6.04 \pm 0.17$ & $139.37 \pm 1.23$ \\
\hline F7 & $151.42 \pm 0.52$ & $10.07 \pm 0.08$ & $1.64 \pm 0.13$ & $99.01 \pm 2.32$ & 0.58 & $3.85 \pm 0.21$ & $6.20 \pm 0.14$ & $|40.55 \pm 2.1|$ \\
\hline F8 & $151.91 \pm 0.36$ & $10.07 \pm 0.09$ & $1.65 \pm 0.09$ & $100.26 \pm 0.50$ & 0.53 & $3.89 \pm 0.20$ & $6.47 \pm 0.15$ & $143.16 \pm 1.97$ \\
\hline F9 & $151.60 \pm 0.86$ & $10.09 \pm 0.06$ & $1.63 \pm 0.15$ & $99.18 \pm 0.96$ & 0.46 & $4.00 \pm 0.16$ & $6.60 \pm 0.25$ & $142.05 \pm \mid .85$ \\
\hline FIO & $150.17 \pm 0.92$ & $10.07 \pm 0.04$ & $1.58 \pm 0.06$ & $|0| .88 \pm 0.61$ & 0.39 & $4.11 \pm 0.09$ & $6.91 \pm 0.25$ & $150.10 \pm 1.73$ \\
\hline FII & $150.46 \pm 0.68$ & $10.08 \pm 0.04$ & $1.6 \mathrm{I} \pm 0.12$ & $102.09 \pm 0.65$ & 0.35 & $4.20 \pm 0.11$ & $6.43 \pm 0.02$ & $\mid 54.66 \pm 2.21$ \\
\hline $\mathrm{FI} 2$ & $149.73 \pm 0.84$ & $10.05 \pm 0.06$ & $1.63 \pm 0.08$ & $99.69 \pm 0.74$ & 0.33 & $4.28 \pm 0.15$ & $6.35 \pm 0.16$ & $166.79 \pm 1.16$ \\
\hline
\end{tabular}

Abbreviations: $\mathrm{BH} .2 \mathrm{HCl}$, betahistine dihydrochloride; SD, standard deviation. 

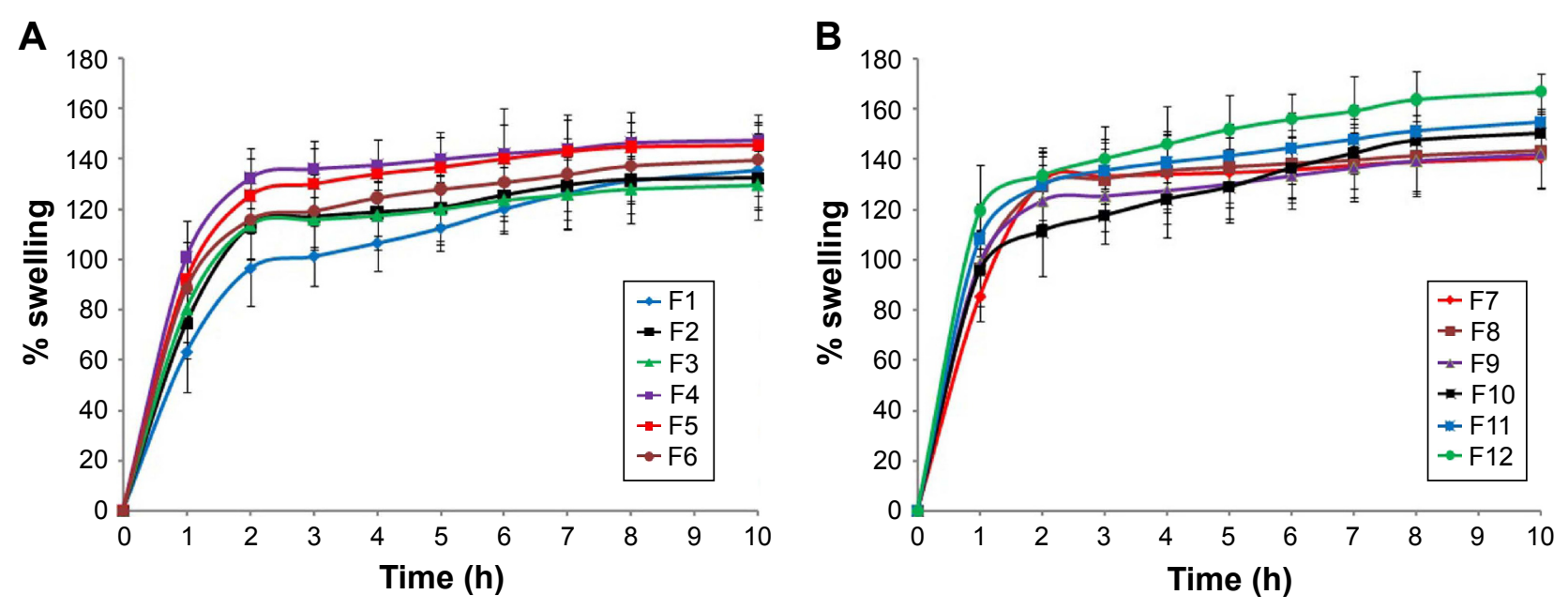

Figure 2 Plot of \% swelling vs time for $\mathrm{BH} .2 \mathrm{HCl}$ mucoadhesive buccal formulations (A) FI-F6 and (B) F7-FI2.

Abbreviation: $\mathrm{BH} .2 \mathrm{HCl}$, betahistine dihydrochloride.

mucoadhesive force. The force $\left(\right.$ dyne $\left./ \mathrm{cm}^{2}\right)$ required for detaching the tablet was measured. The time required for detaching the tablet from the surface of mucosa was recorded as residence time.

Generally, mucoadhesion occurs in four substantial steps: wetting followed by interpenetration, then adsorption and finally secondary chemical bond formation between polymer and mucus membrane. The mucoadhesion strength is influenced by various factors, such as degree of swelling of the polymer, its molecular weight, contact time with mucosal membrane and kind of biological membrane utilized in the study. ${ }^{43}$ The higher the degree of hydration, the higher is the adhesion until certain point where excess hydration leads to a sudden decline in mucoadhesion strength as a result of disentanglement at the polymer/membrane interface.

The mucoadhesion performance was affected by the concentration of the polymers. The mucoadhesive strength and the ex vivo residence time of the prepared formulations were found to increase with increased polymer concentration. The highest mucoadhesive strength was obtained in formulation F12, while F1 exhibited the lowest mucoadhesive strength (Table 3). Also, the results of the mucoadhesion properties of the developed formulations revealed that all tablets showed good attachment to the buccal membrane and that most of the prepared formulations exhibit good mucoadhesive performance.

\section{In vivo testing of the mucoadhesive delivery systems}

The response answers of bitterness, irritation, disintegration, adhesion time and adhesion strength of the mucoadhesive tablets upon their in vivo application to three volunteers are shown in Table 4. Formulations (F1-F3) suffered from certain problems like slight adhesive strength, moderate irritation, moderate bitterness, disintegration and very short adhesion time. Replacement of HPMC K4M with guar gum in the formulations F4-F6 and F10-F12 resulted in better parameters (no or slight irritation, no bitterness, no disintegration, adhesive and reasonable adhesion time of more than $8 \mathrm{~h}$ ). On the other hand, formulations (F7-F9) showed good responses but encountered short adhesion time which ranged from 4.5 to $7 \mathrm{~h}$.

\section{In vitro release study}

Factors such as dissolution and swelling of the polymers (hydrophilic matrices) are very important for drug release where the mass of the system gets eroded along with drug

Table 3 Mucoadhesive strength, force and residence time of $\mathrm{BH} .2 \mathrm{HCl}$ mucoadhesive buccal tablets

\begin{tabular}{|c|c|c|c|}
\hline Formulations & Strength (g) & Force $\left(\right.$ dyne $\left./ \mathrm{cm}^{2}\right)$ & $\begin{array}{l}\text { Residence } \\
\text { time (h) }\end{array}$ \\
\hline $\mathrm{FI}$ & $8.32 \pm 0.02$ & $10,356.50 \pm 0.04$ & $0.75 \pm 0.18$ \\
\hline $\mathrm{F} 2$ & $13.79 \pm 0.03$ & $17,239.01 \pm 0.02$ & $1.08 \pm 0.60$ \\
\hline F3 & $|7.50 \pm 0.0|$ & $21,836.00 \pm 0.01$ & $1.50 \pm 0.49$ \\
\hline $\mathrm{F} 4$ & $66.81 \pm 0.01$ & $83,351.16 \pm 0.01$ & $8.12 \pm 0.30$ \\
\hline F5 & $68.00 \pm 0.01$ & $84,848.48 \pm 0.04$ & $8.20 \pm 0.40$ \\
\hline F6 & $69.16 \pm 0.02$ & $86,345.76 \pm 0.02$ & $8.17 \pm 0.50$ \\
\hline F7 & $19.31 \pm 0.04$ & $24,082.00 \pm 0.02$ & $6.75 \pm 0.33$ \\
\hline F8 & $25.10 \pm 0.01$ & $31,319.12 \pm 0.03$ & $6.50 \pm 0.87$ \\
\hline F9 & $58.25 \pm 0.01$ & $72,745.06 \pm 0.02$ & $4.25 \pm 0.75$ \\
\hline FIO & $98.87 \pm 0.01$ & $|23,404.73 \pm 0.0|$ & $8.21 \pm 0.38$ \\
\hline FII & $101.08 \pm 0.01$ & $|26| 46.77 \pm 0.04$, & $8.14 \pm 1.01$ \\
\hline $\mathrm{FI} 2$ & $103.10 \pm 0.02$ & $|28,645.3| \pm 0.0 \mid$ & $8.40 \pm 0.44$ \\
\hline
\end{tabular}

Note: Data are mean values $(n=3) \pm S D$.

Abbreviations: $\mathrm{BH} .2 \mathrm{HCl}$, betahistine dihydrochloride; SD, standard deviation. 
Table 4 In vivo mucoadhesion properties of $\mathrm{BH} .2 \mathrm{HCl}$ mucoadhesive buccal tablets

\begin{tabular}{llllll}
\hline Formulations & $\begin{array}{l}\text { Adhesion } \\
\text { time (h) }\end{array}$ & $\begin{array}{l}\text { Adhesion } \\
\text { strength }\end{array}$ & Irritation & Bitterness & Disintegration \\
\hline FI & 1 & Slightly adhesive & Moderate & Moderate & High \\
F2 & 1.5 & Slightly adhesive & Moderate & Moderate & High \\
F3 & 2 & Slightly adhesive & Moderate & Moderate & High \\
F4 & $>8$ & Adhesive & Non & Non & Non \\
F5 & $>8$ & Adhesive & Non & Non & Non \\
F6 & $>8$ & Adhesive & Non & Non & Slight \\
F7 & 7 & Moderately adhesive & Non & Non & Slight \\
F8 & 6.5 & Moderately adhesive & Slight & Slight & Moderate \\
F9 & 4.5 & Moderately adhesive & Slight & Slight & Non \\
FI0 & $>8$ & Adhesive & Non & Non & Non \\
FII & $>8$ & Adhesive & Non & Non & Non \\
FI2 & $>8$ & Adhesive & Slight & Non & S
\end{tabular}

Abbreviation: $\mathrm{BH} .2 \mathrm{HCl}$, betahistine dihydrochloride.

dissolution and diffusion. Firstly, an increase in the matrix thickness occurs as a result of presence of the polymer in hydrated and swollen conditions. Secondly, the matrix thickness diminishes and finally disappears because of dissolution of both the polymer and the drug, and such a matrix is known as "swellable soluble matrix". ${ }^{44}$

The release behavior of the prepared formulations (F1-F12) was studied for $8 \mathrm{~h}$, and the results are illustrated in Figure $3 \mathrm{~A}$ and $\mathrm{B}$. There was a variation in the drug release pattern from the prepared formulations according to the ratio and type of the incorporated polymers. Without coating, nearly all drugs were released from all formulations within $1 \mathrm{~h}$.

For formulations (F1-F3) containing 25\%,30\%, and $35 \%$ of HPMC K4M polymer, respectively, it is obvious that the extent of drug release was $99.1 \%, 98.7 \%$ and $96.9 \%$, respectively. Our results revealed a decrease in drug release rate from formulations (F1-F3) with increasing HPMC K4M concentration.

On the other hand, formulations (F4-F6) were prepared by replacing HPMC K4M with $40 \%, 45 \%$ and $50 \%$ of guar gum respectively. The extent of drug release was $100.5 \%$, $99.9 \%$ and $81.4 \%$, respectively. Formulation F6 met the release specifications for the extended release products: $45 \%-75 \%$ within $6 \mathrm{~h}$ and $75 \%-80 \%$ over $8 \mathrm{~h} .{ }^{45} \mathrm{It}$ is clear from these results that guar gum exhibited a successful control in drug release where a retarded drug release was obtained in comparison with HPMC K4M.

Concerning the formulations (F7-F9) containing 15\%, $20 \%$ and $25 \%$ HPMC K4M polymer and guar gum in 1:1 ratio, respectively, the release of $\mathrm{BH} .2 \mathrm{HCl}$ was found to be $99.1 \%, 96.8 \%$ and $81.7 \%$ after $8 \mathrm{~h}$, respectively. This may indicate that formulation F9 complied with the dissolution
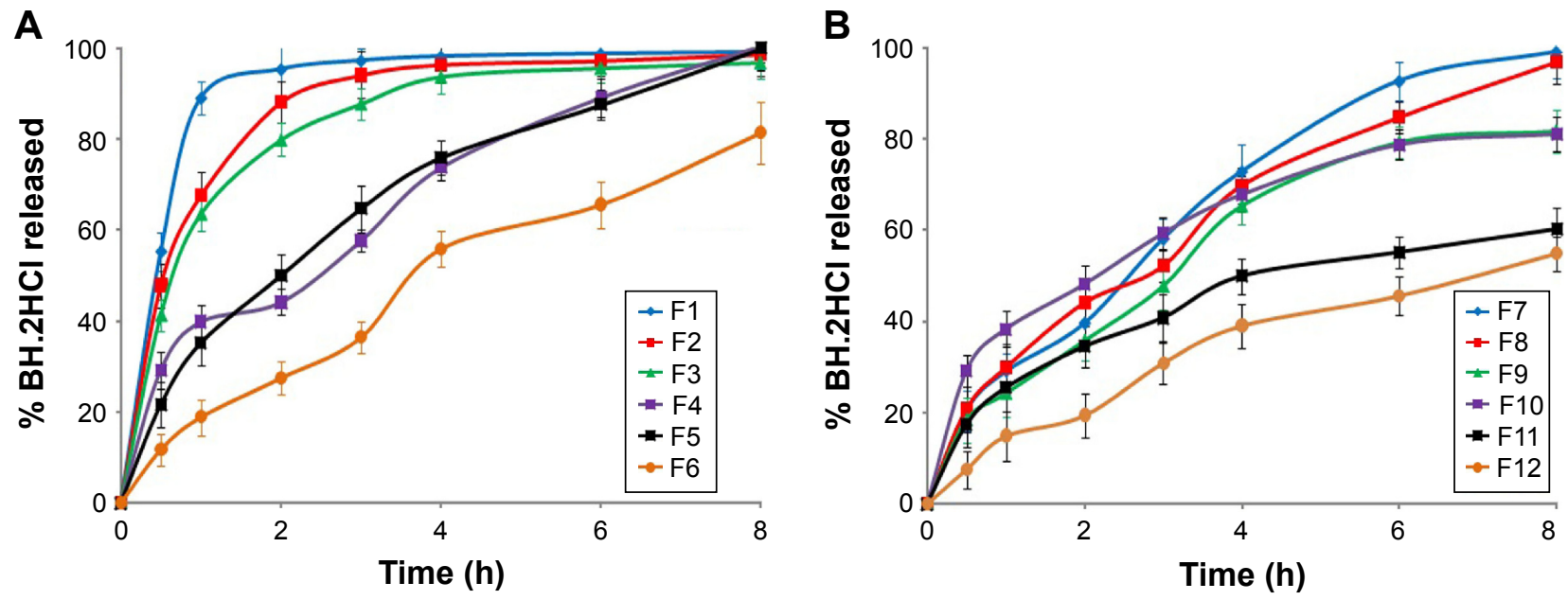

Figure 3 Release profile of $\mathrm{BH} .2 \mathrm{HCl}$ from different mucoadhesive buccal formulations: (A) FI-F6 and (B) F7-FI2. Abbreviation: $\mathrm{BH} .2 \mathrm{HCl}$, betahistine dihydrochloride. 
requirements for controlled release products. Also, it can be observed that addition of guar gum to HPMC K4M decreased the release rate of $\mathrm{BH} .2 \mathrm{HCl}$.

For the formulations (F10-F12) containing fixed percentage of guar gum (35\%) and $5 \%, 10 \%$ and $15 \%$ of $\mathrm{Na}$ CMC respectively, the extent of the drug release was $81.1 \%, 60.2 \%$ and $54.9 \%$, respectively. It was noticed that addition of $\mathrm{Na}$ $\mathrm{CMC}$ to guar gum lowered the rate of $\mathrm{BH} .2 \mathrm{HCl}$ release. A plausible explanation might be that the combination of nonionic guar gum with anionic $\mathrm{Na} \mathrm{CMC}$ created a synergistic elevation of viscosity. This might be related to strong hydrogen bonding between hydroxyl groups of guar gum and the carboxyl groups of $\mathrm{Na} \mathrm{CMC}$ resulting in high crosslinking between the two gums. ${ }^{46}$ Formulations F11 and F12 exhibited lower cumulative percentage of drug release; this could be attributed to extensive swelling which generates a thick gel barrier that hinders and causes an increase in the diffusion path length of drug molecules. ${ }^{42}$

Linear regression analysis of the release data revealed that the release of $\mathrm{BH} .2 \mathrm{HCl}$ from mucoadhesive tablets was in favor of zero-order release kinetics indicating concentration independent drug release, except for formulations F1, F4 and F7 which followed first-order kinetics, while formulations F5 and F6 followed Higuchi equation. This may be due to the tablets containing high concentration of the polymers had formed strong diffusional gel matrix enabling the release of the drug in a controlled manner independent of concentration, while low concentration of polymer matrix (formulations F1, F4 and F7) eroded rapidly, releasing the drug depending upon concentration. For formulations F5 and F6 which contained guar gum, the drug was released by matrix diffusion and not by erosion of the polymer. ${ }^{47}$

The Korsmeyer-Peppas model was used to explain the mechanism of drug release from the prepared tablet formulations. ${ }^{48}$ The empirical Korsmeyer-Peppas power law equation is given as $M_{\mathrm{t}} / M_{\infty}=K_{\mathrm{t}}^{\mathrm{n}}$, where $M_{\mathrm{t}}$ is the amount of drug released at time t, $M_{\infty}$ is the amount released at time $\infty$, $M_{\mathrm{t}} / M_{\infty}$ is the fraction of drug released at time t, $K$ is a constant characteristic of the drug-polymer system and $\mathrm{n}$ is the diffusional exponent, a measure of the primary mechanism of drug release. When $\mathrm{n}$ is equal to 0.5 , the fraction of the drug released is proportional to the square root of time (Higuchi kinetics) and the drug release is solely controlled by diffusion (Fickian diffusion kinetics). A value $\mathrm{n}=1$ indicates drug release is controlled by swelling, a case-II transport (zeroorder kinetics), while the value $0.5<\mathrm{n}<1$ indicates anomalous transport and superposition of both phenomena (non-Fickian kinetic). ${ }^{48}$ For the majority of the prepared formulations, the

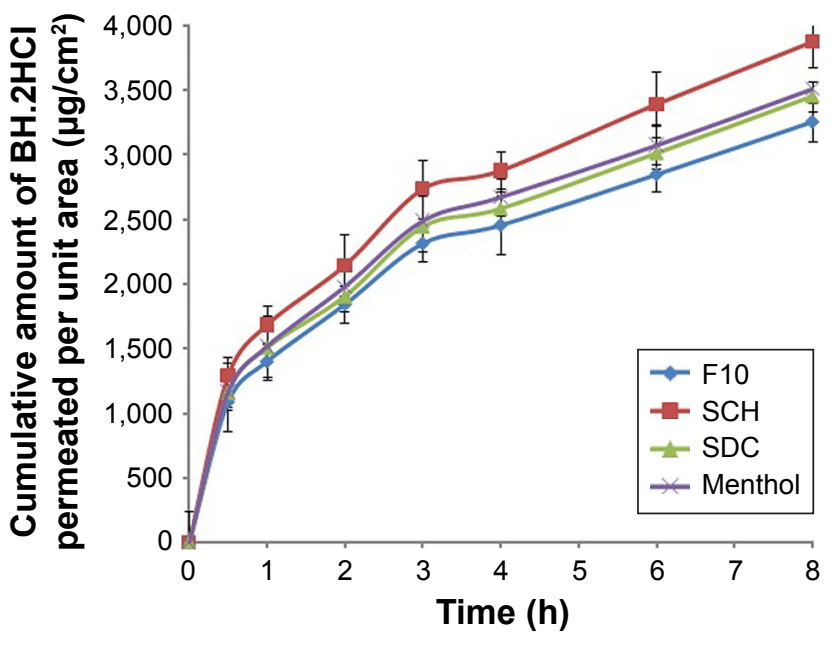

Figure 4 Permeation profile of $\mathrm{BH} .2 \mathrm{HCl}$ from different mucoadhesive buccal formulations.

Abbreviations: $\mathrm{BH} .2 \mathrm{HCl}$, betahistine dihydrochloride; $\mathrm{SCH}$, sodium cholate hydrate; SDC, sodium deoxycholate.

values of $\mathrm{n}$ were found to be approximately 1 , indicating case-II transport where the drug release involves polymer relaxation and chain disentanglement. ${ }^{49}$ The values of $n$ for formulations F5, F6 and F12 ranged from 0.59 to 0.81 , indicating a non-Fickian or anomalous type of transport. Non-Fickian release is described by two mechanisms (a combination of drug diffusion and polymer relaxation), while Fickian release is observed for formulations F1 and F2 in which diffusional release occurs by the usual molecular diffusion of the drug due to a chemical potential gradient. ${ }^{47}$

\section{Ex vivo permeation study}

Formulation F10 exhibited high adhesion strength, long adhesion time and minimal irritation to volunteers. It showed zero-order release kinetics and complied with the release requirements for controlled release tablets. Hence, formulation F10 was selected for further permeation studies. The permeation enhancers, $2 \% \mathrm{SDC}, 2 \% \mathrm{SCH}$ and $5 \%$ menthol, were separately used in the chosen formulation. The results obtained are presented in Figure 4, and the calculated permeation parameters for each formulation are listed in Table 5.

Table 5 Ex vivo permeation parameters of $\mathrm{BH} .2 \mathrm{HCl}$ mucoadhesive buccal tablets

\begin{tabular}{lllll}
\hline Formulations & $Q_{\text {cum }}\left(\mu \mathrm{g} / \mathrm{cm}^{2}\right)$ & Lag time $(\mathrm{min})$ & $K_{\mathrm{p}}(\mathrm{cm} / \mathrm{h})$ & $\mathrm{EF}$ \\
\hline $\mathrm{FIO}$ & $3,255.84 \pm 150.47$ & $51.08 \pm 4.8 \mathrm{I}$ & $0.0085 \pm 0.0012$ & - \\
$\mathrm{SCH}$ & $3,874.56 \pm 195.4 \mathrm{I}$ & $42.1 \mathrm{I} \pm 3.67$ & $0.012 \mathrm{I} \pm 0.0032$ & $\mathrm{I} .42$ \\
$\mathrm{SDC}$ & $3,453.60 \pm \mathrm{I} 14.78$ & $48.05 \pm 2.49$ & $0.0092 \pm 0.0017$ & 1.08 \\
Menthol & $3,509.76 \pm 145.44$ & $44.10 \pm 4.20$ & $0.0090 \pm 0.001 \mathrm{I}$ & 1.06
\end{tabular}

Note: Data are mean values $(n=3) \pm S D$.

Abbreviations: $\mathrm{BH} .2 \mathrm{HCl}$, betahistine dihydrochloride; $\mathrm{EF}$, enhancement factor; $\mathrm{K}_{\mathrm{p}}$, permeability coefficient; $\mathrm{SCH}$, sodium cholate hydrate; SDC, sodium deoxycholate; $\mathrm{SD}$, standard deviation; $Q_{\text {cum }}$, cumulative drug in the receptor compartment. 
The permeation parameters including $Q_{\text {cum }}\left(\mu \mathrm{g} / \mathrm{cm}^{2}\right)$, lag time $(\mathrm{min}), K_{\mathrm{p}}(\mathrm{cm} / \mathrm{h})$ and EF were used to assess the permeation capability of the tested formulations. It can be noticed from the results listed in Table 5 that formulation containing $\mathrm{SCH}$ as a permeation enhancer exhibited significantly higher $(P<0.05)$ buccal mucosa permeation compared with the control formulation (F10) and other permeation enhancers.

Menthol was used as a permeation enhancer in buccal drug delivery due to its safety profile as well as its pleasant taste. In our study, menthol did not significantly enhance permeation. El-Samaligy et $\mathrm{al}^{49}$ reported similar findings regarding diclofenac sodium. SCH and SDC are bile salts that are extensively reported to improve transepithelial permeation of drugs. ${ }^{50} \mathrm{SCH}$ structure differs from SDC in the number of $\mathrm{OH}$ groups, where the former contains three groups while the latter contains only two groups.

Furthermore, in our study 2\% SDC did not produce a significant enhancement in permeation. This is in accordance with Shanker et $\mathrm{al}^{42}$ who reported that buccal mucosal permeation enhancement with SDC occurs only at higher concentration $(3 \%)$, while lower concentrations (1\% and $2 \%$ ) did not enhance permeation.

On the other hand, $2 \% \mathrm{SCH}$ used in this work exerted a significant enhancement in the permeation of $\mathrm{BH} .2 \mathrm{HCl}$, which could be attributed to the ability of the penetration enhancer to work on the protein domain resulting in uncoiling and extending of protein helix; hence, enhanced drug diffusion could occur due to the opening of polar pathway. Also, this buccal permeation enhancement could be attributed to a complicated process involving protein extraction and denaturation, intercellular lipids solubilization, tissue swelling and enzyme inactivation. ${ }^{50}$ Sodium cholate is incorporated in RapidMist ${ }^{\mathrm{TM}}$ spray (Generex Biotechnology Corporation, Canada) which has been utilized for buccal insulin delivery. ${ }^{51}$

\section{Characterization of drug and excipients}

DSC studies were carried out for investigation of physical state of $\mathrm{BH} .2 \mathrm{HCl}$ in the tablets and to examine any possible interactions between $\mathrm{BH} .2 \mathrm{HCl}$ and polymers in the selected formulation $\mathrm{F} 10$ in addition to $\mathrm{SCH}$. Pure $\mathrm{BH} .2 \mathrm{HCl}$ exhibited a sharp melting peak at $149.47^{\circ} \mathrm{C}$ that was not changed in thermogram of the tested formulation, evidencing the absence of interaction (Figure 5A-I).

The IR spectrum of pure $\mathrm{BH} .2 \mathrm{HCl}$ is characterized by major bands in the functional group region at $3,412 \mathrm{~cm}^{-1}$ which is characteristic for $(-\mathrm{NH})$ stretching vibration, at $1,446 \mathrm{~cm}^{-1}$ for $(\mathrm{C}=\mathrm{N})$ stretching and at $1,626 \mathrm{~cm}^{-1}$ for $\mathrm{C}=\mathrm{C}$ stretching. ${ }^{52}$

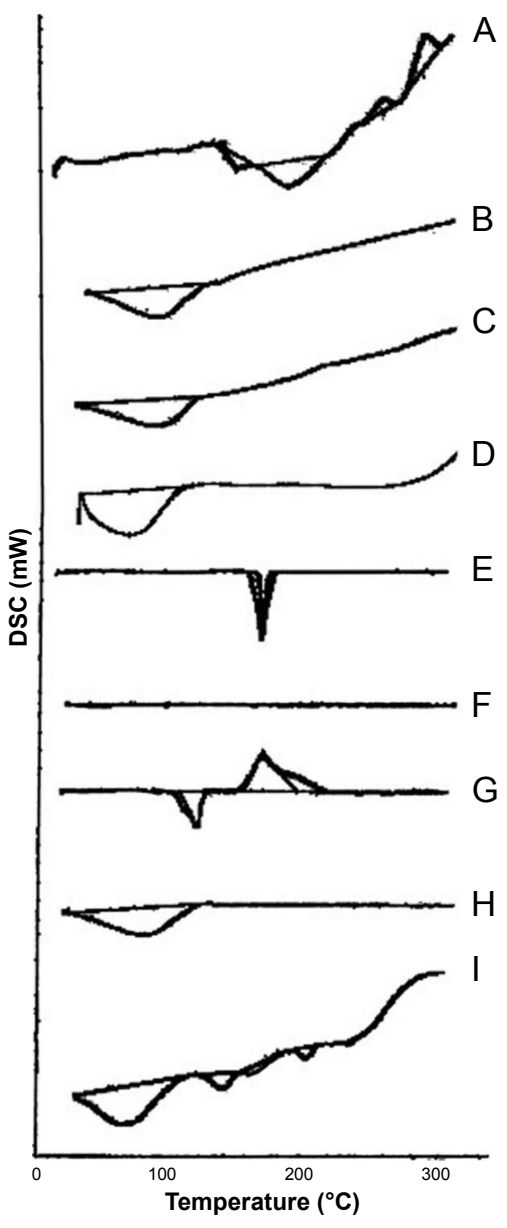

Figure 5 DSC thermograms of $(\mathbf{A})$ pure $\mathrm{BH} .2 \mathrm{HCl}$, (B) guar gum, (C) $\mathrm{Na} C M C$, (D) HPMC K4M, (E) mannitol, (F) Aerosil 200, (G) magnesium stearate (H) SCH and (I) formulation $\mathrm{FIO}$ in addition to $\mathrm{SCH}$.

Abbreviations: $\mathrm{BH} .2 \mathrm{HCl}$, betahistine dihydrochloride; DSC, differential scanning calorimetry; HPMC K4M, hydroxypropyl methyl cellulose grade K4M; Na CMC, sodium carboxymethyl cellulose; $\mathrm{SCH}$, sodium cholate hydrate.

It is clear from the IR spectrum of the optimized formulation that the drug and excipients exhibit the same distinguishing bands in the same regions and at the same ranges but may be with decreasing intensity due to dilution, and no new bands are observed. This might be indicative of lack of any signs of chemical interaction of $\mathrm{BH} .2 \mathrm{HCl}$ with the incorporated excipients (Figure 6A-I).

\section{Stability testing}

None of the tablets stored at $40^{\circ} \mathrm{C}$ and $60^{\circ} \mathrm{C} \pm 0.5^{\circ} \mathrm{C}$ with relative humidity $75 \%$ for a period of 12 weeks exhibited any alterations in appearance or color during storage. Figure 7 shows a typical chromatogram for $\mathrm{BH} .2 \mathrm{HCl}$ in the mobile phase, which was detected at $\lambda_{\text {max }} 260 \mathrm{~nm}$. BH.2 HCl was well separated and its retention time was $3.65 \mathrm{~min}$. The peak was symmetrical, sharp and showed good resolution at baseline with minimal tailing; hence, the peak area could be accurately measured. A highly 


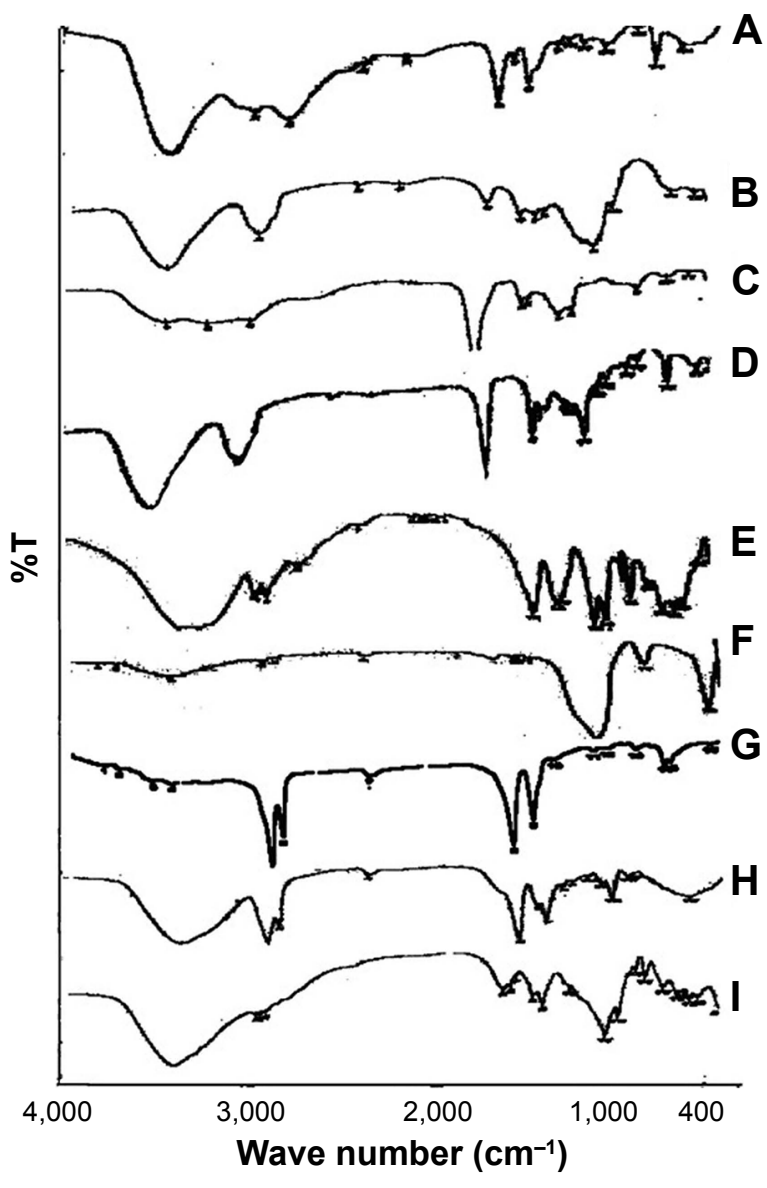

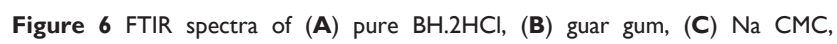
(D) HPMC K4M, (E) mannitol, (F) Aerosil 200, (G) magnesium stearate (H) SCH and (I) formulation $\mathrm{FIO}$ in addition to $\mathrm{SCH}$.

Abbreviations: $\mathrm{BH} .2 \mathrm{HCl}$, betahistine dihydrochloride; $\mathrm{FTIR}$, fourier-transform infrared spectroscopy; HPMC K4M, hydroxypropyl methyl cellulose grade K4M; $\mathrm{Na} \mathrm{CMC}$, sodium carboxymethyl cellulose; $\mathrm{SCH}$, sodium cholate hydrate.

linear calibration plot was obtained within the concentration range used with a correlation coefficient of 0.9981 .

The chemical stability results of the optimized formulation of BH.2 $\mathrm{HCl}$ mucoadhesive tablet showed very low drug degradation rate at the two elevated temperatures where the percent drug remaining was $98.42 \%$ and $96.61 \%$ at $40^{\circ} \mathrm{C}$ and $60^{\circ} \mathrm{C}$, respectively (Table 6). Stability data regression analysis revealed that drug decomposition followed first-order kinetics as shown in Figure 8. Calculation of the degradation rate constant $\left(K_{25}\right)$ was carried out, and the Garret and Karper equation was employed for determination of the expiration date, which states: $\mathrm{t}_{90 \%}=0.105 / K_{25}$, where $\mathrm{t}_{90 \%}$ is the time at which the percent drug remaining is $90 \% .^{32}$ The expiration date of the buccal tablets was 3.06 years. Additionally, no change in the drug release from the stored formulation was observed during the storage period at $40^{\circ} \mathrm{C}$ and $75 \%$ relative humidity. Moreover, there was an insignificant change in the mucoadhesive strength of the stored tablets $(P>0.05)$.

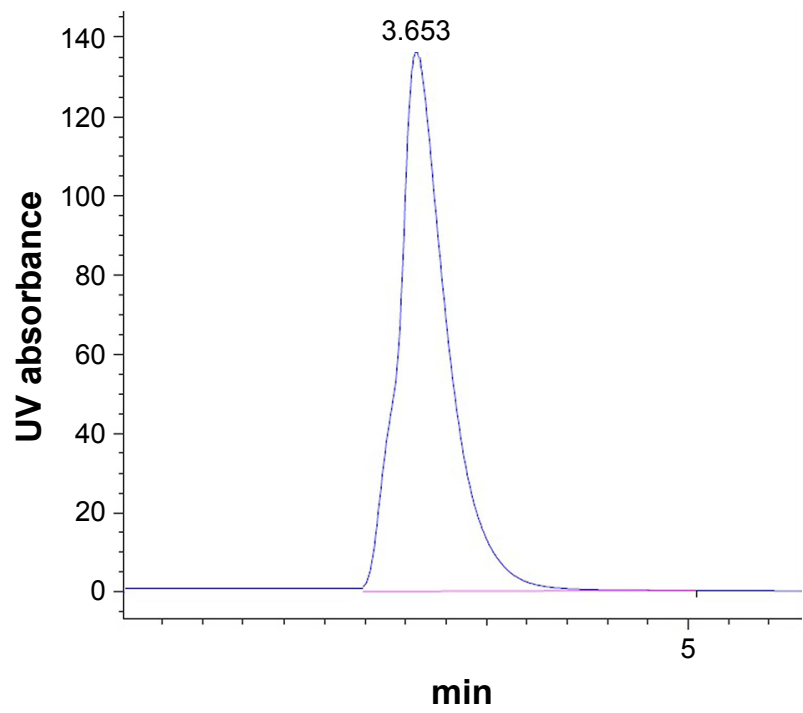

Figure 7 Chromatogram of $\mathrm{BH} .2 \mathrm{HCl}$ in the mobile phase at $\lambda_{\text {max }} 260 \mathrm{~nm}$. Abbreviations: $\mathrm{BH} .2 \mathrm{HCl}$, betahistine dihydrochloride; min, minutes.

\section{Bioavailability study}

Figure 9 shows the mean $\mathrm{BH} .2 \mathrm{HCl}$ plasma concentrationtime curves after administering the optimized mucoadhesive buccal formulation and Betahistine dihydrochloride tablets. The optimized buccal formulation and Betahistine dihydrochloride tablets showed mean peak plasma concentrations of 106.31 and $151.95 \mathrm{ng} / \mathrm{mL}$ obtained within 6.2 and $2.5 \mathrm{~h}$, respectively. The mean areas under the plasma concentration-time curves were calculated to be $1,540.33$ and $870.23 \mathrm{ng} \cdot \mathrm{h} / \mathrm{mL}$, respectively. The optimized $\mathrm{BH} .2 \mathrm{HCl}$ buccal formulation exhibited percentage relative bioavailability of $177 \%$ compared to that of the commercially available Betahistine dihydrochloride tablets.

An in vivo study demonstrated that the buccal formulation attained delayed $t_{\max }$ and lowered $c_{\max }$ values as well as a prolonged mean elimination half-life in comparison with that of

Table 6 Percentage of $\mathrm{BH} .2 \mathrm{HCl}$ remained in formulation FIO when stored at different temperatures $\left(40^{\circ} \mathrm{C}\right.$ and $\left.60^{\circ} \mathrm{C}\right)$ for 12 weeks

\begin{tabular}{llc}
\hline Time (weeks) & $\begin{array}{l}\text { Percentage of the drug remained } \\
\text { in formulation FI } 0 \text { when stored at } \\
\text { temperatures of }\end{array}$ \\
\cline { 2 - 3 } & $\mathbf{4 0 ^ { \circ } \mathrm { C }}$ & $\mathbf{6 0 ^ { \circ } \mathrm { C }}$ \\
\hline 0 & $101.88 \pm 0.61$ & $101.88 \pm 0.61$ \\
1 & $99.61 \pm 0.88$ & $99.45 \pm 1.11$ \\
2 & $99.45 \pm 1.02$ & $99.09 \pm 0.65$ \\
4 & $99.19 \pm 0.87$ & $98.69 \pm 1.14$ \\
6 & $98.95 \pm 1.00$ & $98.18 \pm 0.82$ \\
8 & $98.81 \pm 0.69$ & $97.82 \pm 1.29$ \\
12 & $98.42 \pm 0.95$ & $96.61 \pm 0.67$ \\
\hline
\end{tabular}

Abbreviation: $\mathrm{BH} .2 \mathrm{HCl}$, betahistine dihydrochloride. 


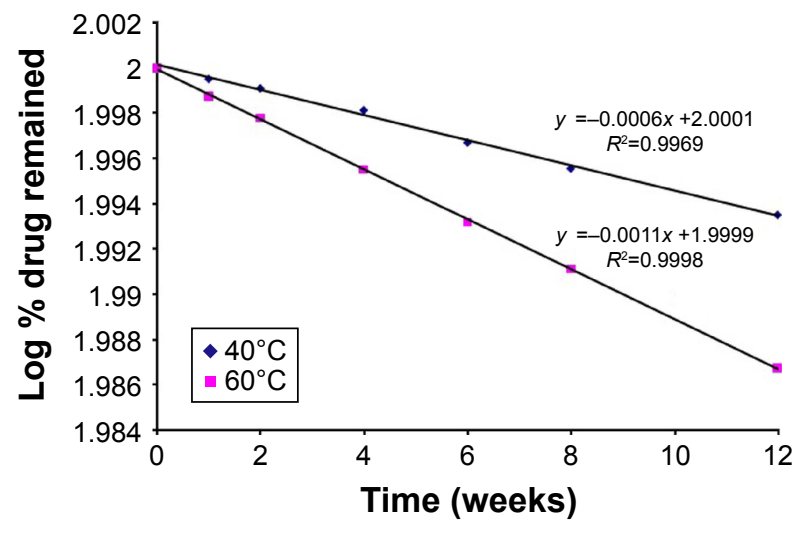

Figure 8 Plot of log $\% \mathrm{BH} .2 \mathrm{HCl}$ remained vs time after storage of the optimized buccal formulation for 12 weeks at $40^{\circ} \mathrm{C}$ and $60^{\circ} \mathrm{C}$ according to first-order kinetics. Abbreviation: $\mathrm{BH} .2 \mathrm{HCl}$, betahistine dihydrochloride.

Betahistine dihydrochloride tablets (Table 7). The buccal formulation showed a $t_{1 / 2}$ of $6.78 \mathrm{~h}$, while Betahistine dihydrochloride tablets attained $t_{1 / 2}$ of $3.1 \mathrm{~h}$. $\mathrm{BH} .2 \mathrm{HCl}$ buccal formulation showed a slow release of the drug in the buccal cavity which might result in its prolonged plasma levels and elimination half-life as observed from the pharmacokinetic results. As a result, the developed $\mathrm{BH} .2 \mathrm{HCl}$ unidirectional mucoadhesive buccal formulation might be beneficial in supplying minimal fluctuations along with constant drug delivery.

The results of the present study revealed a significant difference between the pharmacokinetic parameters $\left(t_{1 / 2}, \mathrm{AUC}_{0-20}\right.$ and $\left.\mathrm{AUC}_{0-\infty}\right)$ of the buccal formulation compared to the oral Betahistine dihydrochloride $(24 \mathrm{mg}$ ) tablets. It is clear that the buccal formulation generated 1.77-fold increase in the bioavailability in comparison with the oral tablets. The buccal formulation exhibited a significant higher bioavailability

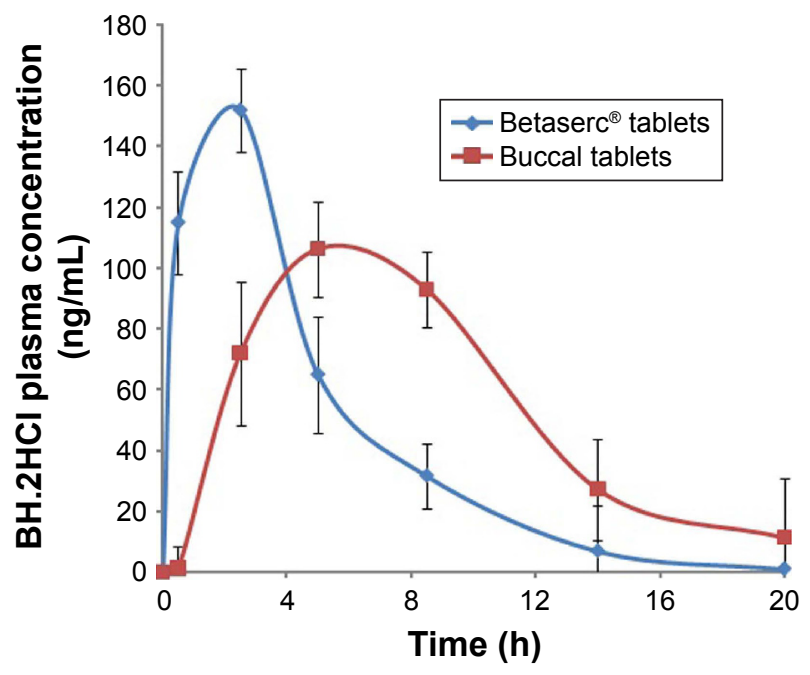

Figure $9 \mathrm{BH} .2 \mathrm{HCl}$ plasma concentrations following the administration of the optimized buccal formulation and oral tablets Betaserc ${ }^{\circledR} 24 \mathrm{mg}$. Abbreviation: $\mathrm{BH} .2 \mathrm{HCl}$, betahistine dihydrochloride.
Table 7 Mean pharmacokinetic parameters for the volunteers following administration of the optimized mucoadhesive buccal formulation and oral Betaserc ${ }^{\circledR}$ tablets

\begin{tabular}{lll}
\hline $\begin{array}{l}\text { Pharmacokinetic } \\
\text { parameters }\end{array}$ & Mean \pm SD & \\
\cline { 2 - 3 } & FIO & Betaserc tablet \\
\hline$C_{\text {max }}(\mathrm{ng} / \mathrm{mL})$ & $106.31 \pm 9.12$ & $151.95 \pm 10.28$ \\
$t_{\text {max }}(\mathrm{h})$ & $6.17 \pm 2.02$ & $2.50 \pm 0.96$ \\
$K_{\text {elim }}\left(\mathrm{h}^{-1}\right)$ & $0.1022 \pm 0.037 \mathrm{I}$ & $0.2235 \pm 0.024 \mathrm{I}$ \\
$T_{1 / 2}(\mathrm{~h})$ & $6.78 \pm 0.87$ & $3.10 \pm 0.23$ \\
$\mathrm{AUC}_{0-20}(\mathrm{ng} \cdot \mathrm{h} / \mathrm{mL})$ & $1,313.50 \pm 225.77$ & $866.65 \pm 144.34$ \\
$\mathrm{AUC}_{0-\infty}(\mathrm{ng} \cdot \mathrm{h} / \mathrm{mL})$ & $1,540.33 \pm 270.95$ & $870.23 \pm 157.77$ \\
$F_{\text {rel }}(\%)$ & $177.00 \pm \mathrm{II} .02$ & - \\
\hline
\end{tabular}

Abbreviations: AUC, area under the curve; SD, standard deviation.

as compared to the oral tablet, which might be related to avoidance of first-pass effect and increase in permeability due to the presence of $\mathrm{SCH}$ which acts as a penetration enhancer.

\section{Conclusion}

In this study, stable mucoadhesive buccal tablets of $\mathrm{BH} .2 \mathrm{HCl}$ with a unidirectional drug flow were prepared using a combination of $35 \%$ guar gum and $5 \% \mathrm{Na} \mathrm{CMC}$, which resulted in controlled drug delivery. Addition of $2 \% \mathrm{SCH}$ significantly enhanced the permeation of $\mathrm{BH} .2 \mathrm{HCl}$ across the buccal mucosa and produced a significant elevation of its bioavailability in comparison with orally administered tablets (Betahistine dihydrochloride $24 \mathrm{mg}$ ). Hence, mucoadhesive buccal delivery of $\mathrm{BH} .2 \mathrm{HCl}$ could be considered as a successful surrogate to bypass the hepatic metabolism and attain controlled release, leading to reduced demand of repeated administration and enhanced patient compliance.

\section{Acknowledgments}

The authors would like to thank Dr Mohammed H El komy, Department of Pharmaceutics and Industrial Pharmacy, Faculty of Pharmacy, Beni-Suef University, for his help throughout the study. They are also grateful to Dr Reda Abd Allah, Department of Anatomy and Embryology, Faculty of Veterinary Medicine, Beni-Suef University, for helping in trimming buccal mucosa used in the study.

\section{Disclosure}

The authors report no conflicts of interest in this work.

\section{References}

1. Dhiman MK, Dhiman A, Sawant KK. Transbuccal delivery of 5-fluorouracil: permeation enhancement and pharmacokinetic study. AAPS PharmSciTech. 2009;10(1):258-265.

2. Jagdale SC, Mohanty P, Chabukswar AR, Kuchekar BS. Dissolution rate enhancement, design and development of buccal drug delivery of darifenacin hydroxypropyl $\beta$-cyclodextrin inclusion complexes. J Pharm (Cairo). 2013;2013:983702. 
3. Lodhi M, Dubey A, Narayan R, Prabhu P, Priya S. Formulation and evaluation of buccal film of Ivabradine hydrochloride for the treatment of stable angina pectoris. Int J Pharm Investig. 2013;3(1):47-53.

4. Rosen T. Pragmatic and profound benefits of acyclovir buccal adhesive tablets. J Drugs Dermatol. 2016;15(6):775-777.

5. Bahri-Najafi R, Tavakoli N, Senemar M, Peikanpour M. Preparation and pharmaceutical evaluation of glibenclamide slow release mucoadhesive buccal film. Res Pharm Sci. 2014;9(3):213-223.

6. Patel VM, Prajapati BG, Patel JK, Patel MM. Physicochemical characterization and evaluation of buccal adhesive patches containing propranolol hydrochloride. Curr Drug Deliv. 2006;3(3):325-331.

7. Shin SC, Bum JP, Choi JS. Enhanced bioavailability by buccal administration of triamcinolone acetonide from the bioadhesive gels in rabbits. Int J Pharm. 2000;209(1-2):37-43.

8. Mahalingam R, Ravivarapu H, Redkar S, Li X, Jasti BR. Transbuccal delivery of 5-aza-2-deoxycytidine: effects of drug concentration, buffer solution, and bile salts on permeation. AAPS PharmSciTech. 2007; 8(3):E55.

9. Choi HG, Kim CK. Development of omeprazole buccal adhesive tablets with stability enhancement in human saliva. J Control Release. 2000;68(3):397-404.

10. Choi H, Jung J, Yong CS, et al. Formulation and in vivo evaluation of omeprazole buccal adhesive tablet. J Control Release. 2000;68(3): 405-412.

11. Singh B, Ahuja N. Development of controlled-release buccoadhesive hydrophilic matrices of diltiazem hydrochloride: optimization of bioadhesion, dissolution, and diffusion parameters. Drug Dev Ind Pharm. 2002;28(4):431-442.

12. Barak N, Beck Y, Albeck JH. A randomized, double-blind, placebocontrolled pilot study of betahistine to counteract olanzapine-associated weight gain. J Clin Psychopharmacol. 2016;36(3):253-256.

13. Hathout RM, Nasr M. Transdermal delivery of betahistine hydrochloride using microemulsions: physical characterization, biophysical assessment, confocal imaging and permeation studies. Colloids Surf B Biointerfaces. 2013;110:254-260.

14. Shamma RN, Basalious EB, Shoukri RA. Development and optimization of a multiple-unit controlled release formulation of a freely water soluble drug for once-daily administration. Int J Pharm. 2011; 405(1-2):102-112.

15. Heda AA, Sonawane AR, Naranje GH, Somani VG, Pauranik PK. Development and in vitro evaluation of betahistine adhesive-type transdermal delivery system. Trop J Pharm Res. 2010;9(6):516-524.

16. Rao YM, Veni JK, Jayasagar G. Formulation and evaluation of diclofenac sodium using hydrophilic matrices. Drug Dev Ind Pharm. 2001; 27(8):759-766.

17. Ali AA, Sayed OM. Development and characterization of ketorolac tromethamine osmotic pump tablets. J Drug Del Sci Tech. 2013;23(3): $275-281$.

18. Zhang ZH, Dong HY, Peng B, et al. Design of an expert system for the development and formulation of push-pull osmotic pump tablets containing poorly water-soluble drugs. Int J Pharm. 2011;410(1-2): $41-47$.

19. Aboud HM, Ali AA, Abd Elbary A. Formulation and optimization of tenoxicam orodispersible tablets by solid deposition technique. J Drug Del Sci Tech. 2012;22(6):555-561.

20. Patel VM, Prajapati BG, Patel MM. Formulation, evaluation and comparison of bilayered and multilayered mucoadhesive buccal devices of propranolol hydrochloride. AAPS PharmSciTech. 2007; 8(1):E147-E154.

21. Ritthidej GC, Phaechamud T, Koizumi T. Moist heat treatment on physicochemical change of chitosan salt films. Int J Pharm. 2002; 232(1):11-22.

22. De Caro V, Scaturro AL, Di Prima G, et al. Aloin delivery on buccal mucosa: ex vivo studies and design of a new locoregional dosing system. Drug Dev Ind Pharm. 2015;41(9):1541-1547.
23. Mylangam CK, Beeravelli S, Medikonda J, Pidaparthi JS, Kolapalli VR. Badam gum: a natural polymer in mucoadhesive drug delivery. Design, optimization, and biopharmaceutical evaluation of badam gum-based metoprolol succinate buccoadhesive tablets. Drug Deliv. 2016;23(1):195-206.

24. El-Mahrouk GM, El-Gazayerly ON, Aboelwafa AA, Taha MS. Chitosan lactate wafer as a platform for the buccal delivery of tizanidine $\mathrm{HCl}$ : in vitro and in vivo performance. Int J Pharm. 2014;467(1-2): 100-112.

25. De Caro V, Giandalia G, Siragusa MG, Giannola LI. Buccal delivery of methimazole as an alternative means for improvement of drug bioavailability: permeation studies and matrix system design. Curr Pharm Des. 2012;18(34):5405-5410.

26. Panda B, Subhadarsini R, Mallick S. Biointerfacial phenomena of amlodipine buccomucosal tablets of HPMC matrix system containing polyacrylate polymer/ $\beta$-cyclodextrin: correlation of swelling and drug delivery performance. Expert Opin Drug Deliv. 2016;13(5):633-643.

27. Palem CR, Gannu R, Yamsani SK, Yamsani VV, Yamsani MR. Development of bioadhesive buccal tablets for felodipine and pioglitazone in combined dosage form: in vitro, ex vivo, and in vivo characterization. Drug Deliv. 2011;18(5):344-352.

28. Pathak K, Sharma V, Akhtar N, Rastogi P. Localization of fluconazole in oral cavity by preferential coating of buccoadhesive tablet for treatment of oral thrush. Int J Pharm Investig. 2016;6(2):106-115.

29. Aboud HM, El Komy MH, Ali AA, El Menshawe SF, Abd Elbary A. Development, optimization, and evaluation of carvedilol-loaded solid lipid nanoparticles for intranasal drug delivery. AAPS PharmSciTech. Epub 2016 Jan 7.

30. Shin SC, Kim JY. Enhanced permeation of triamcinolone acetonide through the buccal mucosa. Eur J Pharm Biopharm. 2000;50(2):217-220.

31. Khedr A, Sheha M. Stress degradation studies on betahistine and development of a validated stability-indicating assay method. J Chromatogr B Analyt Technol Biomed Life Sci. 2008;869(1-2):111-117.

32. Anderson G, Scott M. Determination of product shelf life and activation energy for five drugs of abuse. Clin Chem. 1991;37(3):398-402.

33. Abdelbary A, El-Gazayerly ON, El-Gendy NA, Ali AA. Floating tablet of trimetazidine dihydrochloride: an approach for extended release with zero-order kinetics. AAPS PharmSciTech. 2010;11(3): 1058-1067.

34. Ahmed TA, El-Say KM, Mahmoud MF, Samy AM, Badawi AA. Miconazole nitrate oral disintegrating tablets: in vivo performance and stability study. AAPS PharmSciTech. 2012;13(3):760-771.

35. Estrada-Marín L, Cedillo-Carvallo B, Herrera-Coca A, Bravo-Barragán G, García OG, Ruiz-Argüelles A. Bioequivalence of two oral tablet formulations of betahistine $24 \mathrm{mg}$ : single-dose, open-label, randomized, two-period crossover comparison in healthy individuals. J Bioequiv Availab. 2015;7(1):1-4.

36. The Pharmacopoeia of the United States of America 27, The National Formulary 22, Asian Edition. Rockville, MD: Pharmacopoeial Convention, Inc.; 2004:454-458.

37. Bakan JA. Capsule part III, Microencapsulation. In: Lachmann L, Lieberman HA, Kanig JL, editors. The Theory and Practice of Industrial Pharmacy. 3rd ed. Philadelphia: Lea and Febiger; 1986:412-429.

38. Gavin A, Pham JT, Wang D, Brownlow B, Elbayoumi TA. Layered nanoemulsions as mucoadhesive buccal systems for controlled delivery of oral cancer therapeutics. Int J Nanomedicine. 2015;10:1569-1584.

39. Jelvehgari M, Valizadeh H, Jalali Motlagh R, Montazam H. Formulation and physicochemical characterization of buccoadhesive microspheres containing diclofenac sodium. Adv Pharm Bull. 2014;4(3):295-301.

40. Maurya SK, Bali V, Pathak K. Bilayered transmucosal drug delivery system of pravastatin sodium: statistical optimization, in vitro, ex vivo, in vivo and stability assessment. Drug Deliv. 2012;19(1):45-57.

41. Lehr CM, Bouwstra JA, Schacht EH, Junginger HE. In vitro evaluation of mucoadhesive properties of chitosan and some other natural polymers. Int J Pharm. 1992;78:43-48. 
42. Shanker G, Kumar CK, Gonugunta CS, Kumar BV, Veerareddy PR. Formulation and evaluation of bioadhesive buccal drug delivery of tizanidine hydrochloride tablets. AAPS PharmSciTech. 2009;10(2): 530-539.

43. Nafee NA, Ismail FA, Boraie NA, Mortada LM. Mucoadhesive delivery systems. I. Evaluation of mucoadhesive polymers for buccal tablet formulation. Drug Dev Ind Pharm. 2004;30(9):985-993.

44. Chattaraj SC, Das SK. Effect of formulation variables on dissolution profile of diclofenac sodium from ethyl- and hydroxypropylmethyl cellulose tablets. Drug Dev Ind Pharm. 1996;22(7):555-559.

45. Sievert B, Siewert M. Dissolution test for extended release products. In: Dressman JB, Lennernäs H, editors. Oral Drug Absorption: Prediction and Assessment. New York: Marcel Dekker; 2000:183-195.

46. Nafee NA, Ismail FA, Boraie NA, Mortada LM. Mucoadhesive delivery systems. II. Formulation and in-vitro/in-vivo evaluation of buccal mucoadhesive tablets containing water-soluble drugs. Drug Dev Ind Pharm. 2004;30(9):995-1004.

47. Saindane NS, Pagar KP, Vavia PR. Nanosuspension based in situ gelling nasal spray of carvedilol: development, in vitro and in vivo characterization. AAPS PharmSciTech. 2013;14(1):189-199.
48. Pund S, Rasve G, Borade G. Ex vivo permeation characteristics of venlafaxine through sheep nasal mucosa. Eur J Pharm Sci. 2013;48(1-2): 195-201.

49. El-Samaligy MS, Yahia SA, Basalious EB. Formulation and evaluation of diclofenac sodium buccoadhesive discs. Int J Pharm. 2004;286(1-2): 27-39.

50. Aboud HM, Ali AA, El-Menshawe SF, Elbary AA. Nanotransfersomes of carvedilol for intranasal delivery: formulation, characterization and in vivo evaluation. Drug Deliv. 2016;23(7):2471-2481.

51. Bernstein G. Delivery of insulin to the buccal mucosa utilizing the RapidMist system. Expert Opin Drug Deliv. 2008;5(9):1047-1055.

52. Wagh VD, Pawar N. Development and evaluation of sustained release tablet of betahistine hydrochloride using ion exchange resin tulsion $\mathrm{t} 344$ ISRN Pharm. 2012;2012:438342.

\section{Publish your work in this journal}

Drug Design, Development and Therapy is an international, peerreviewed open-access journal that spans the spectrum of drug design and development through to clinical applications. Clinical outcomes, patient safety, and programs for the development and effective, safe, and sustained use of medicines are the features of the journal, which has also been accepted for indexing on PubMed Central. The manuscript management system is completely online and includes a very quick and fair peer-review system, which is all easy to use. Visit http://www.dovepress.com/testimonials.php to read real quotes from published authors.

Submit your manuscript here: http://www.dovepress.com/drug-design-development-and-therapy-journal 